\title{
Waldemar Ferreira e a Évolução Doutrinal do Direito Mercantil
}

\author{
António Martins Filho \\ Professor Catedrático de Direito Comercial da \\ Faculdade de Direito do Ceará
}

Simples análise da evolução doutrinal do direito brasileiro, no decorrer dos três últimos decênios, faz de logo realçar a posição de excepcional relevância que assume a personalidade de Waldemar Ferreira, na especialização a que afanosamente se dedica.

Evidentemente, o emérito professor da Universidade de São Paulo, sôbre constituir verdadeira expressão de cultura e de operosidade, é hoje o comercialista mais autorizado e o de maior projecção nas letras jurídicas nacionais.

A consagradora autoridade, que o consenso geral the reconhece, assenta os seus fundamentos basilares em duas circunstâncias essenciais. Ressalta a primeira da extensão admirável de sua obra, amplamente difundida e compulsada. Representa a segunda o equilíbrio e percuciência com que apreende e focaliza os múltiplos e complexos fenômenos atinentes aos novos rumos da atividade mercantil, fenômenos que, dinamizados pelas exigências da economia moderna, reclamam, de um lado, a disciplina jurídica correspondente e, de outro, a interpretação doutrinária adequada e consentânea com a finalidade do direito.

Em verdade, uma ordem econômica acentuadamente dinâmica não poderia ajustar-se a um ordenamento ju- 
rídico retardatário ou estático. $E^{\prime}$ que a intensidade das relações da vida coletiva, manifestada através dos agentes da actividade industrial - na mais genérica accepção dêste termo - passa a exercer forte pressão sôbre o direito legisferado, de modo a que sejam supridas as lacunas e, pois, se harmonize a norma à realidade dos factos.

Desse modo, na sócio-esfera em que se expande a dinâmica jurídica avulta e se destaca a acção do doutrinador, em função da necessidade de plasmar novos institutos ou de adaptar os existentes às contingências ambienciais, para o que muitas vezes é levado a romper com a tradição, desprezando razões de ordem científica e recorrendo a construções técnicas especializadas.

Nesse plano superior da elaboração doutrinária do direito, de influências decisivas no equilíbrio e harmonia social, o Professor Waldemar Ferreira merece em verdade o qualificativo de Mestre.

Através de um confronto isolado, pràticamente realizável, qualquer de suas obras poderá assemelhar-se a outras que, igualmente, enriquecem a nossa literatura jurídica.

Analisadas, porém, no duplo sentido horizontal e vertical, assumem proporções inexcedíveis que justificam, suficientemente, a posição de liderança em que ora se encontra o insigne comercialista brasileiro.

Não é o direito uma simples resultante do arbitrio ou manifestação expontânea dos quadros legislativos. Como bem acentuou J. X. Carvalho de Mendonça, ele "se desenvolve no terreno social, num ambiente histórico em relação ao grau de civilização, aos usos e costumes, à organização política dos Estados"(1).

(1) Tratado de Direito Comercial Brasileiro, 3a. ed., vol. I. págs. 49 e 50 . 
Em consequência disso, a história do Direito Comercial brasileiro, atendendo-se às condições econômicas, políticas e sociais que, directa ou indirectamente, concorreram para a sua formação, poder-se-á dividir em quatro fases distintas.

Abrange a primeira o período anterior a 1850 ou seja o da "herança colonial" em que, do ponto de vista doutrinário, ocupa o primeiro plano o nome sempre lembrado de José da Silva lisboa, Visconde de Cairu. Princípios de Direito Mercantil e Leis de Marinha, além de reflectir sólida cultura jurídica especializada e vastos conhecimentos da ciência econômica, é obra que assinala uma época e, sob determinados aspectos, ainda se conserva admiràvelmente actualizada. Regras da Praça, coligidas logo após a abertura dos portos ao comércio das nações amigas, e sòmente publicadas em 1832, são apontadas como o primeiro trabalho jurídico de cunho genuinamente nacional.

A segunda fase histórica inaugura-se com a promulgação do Código Comercial do Império do Brasil e se estende até 1890. Já aúl alguns trabalhos de doutrina merecem especial menção, notadamente o Código Comercial anotado, do Conselheiro Orlando; os Aditamentos ao Código Comercial, do insigne TeixeIra de Freitas. Seguros Marítimos e Contas Correntes, de José da Silva Costa: Marcas de Fábrica e Sociedades Anónimas, de Díbimo DA VeIga Júnior; Títulos ao portador, de Inglês de Souza a bem assim os opúsculos Direito Cambial, de Sousa Pinto; A letra de câmbio e Contratos e obrigações, de Liberato Barrosio, etc.

Nesșe periodo histórico, especialmente nos seus dias finais, prepondera decisivamente a influência da doutrina francesa, que assume maiores proporções em Pardessus, Massé, Delamarre et Leportivin, Beslay, Boistel e, por fim Lyon Caen et RÉNault.

Irrompe a terceira fase de evolução do Direito Mercantil brasileiro no ano imediato à proclamação da Repú- 
blica e vai até ao advento da Revolução de 1930, época em que se observa, nos quadros nacionais, o início de uma nova ordem politica, económica e social.

Na verdade, trabalho magistral de Carlos de Carvalho de logo transformado no Decreto $n .^{\circ} 917$, de 1890, além de. revogar a Parte III do Código de Comércio, imprimiu orientação nova e de cunho científico ao instituto da falência, abrindo-se, em consequência, amplos horizontes e maiores perspectivas aos nossos doutrinadores.

Inaugurado tão auspiciosamente, pode-se afirmar, sem receio de contestação que esse terceiro período é precisamente o de maior importância e o mais decisivo no que tange à autonomia doutrinal do nosso Direito Mercantil.

Nele, com efeito, surgem ou se agigantam os nomes dos mais consplicuos comercialistas pátrios, notadamente Silva Costa, José António Saraiva, Rodrigo Octávio, Patlo de Lacerda, Inglês de Souza, João Arruda, Magarinos Torres, Bento de Faria, Alfredo Russel, Spencer Vampré e, mais tarde, Waldemar Ferreira, Almáquio Diniz, José Maria Whitaker e outros.

Merece especial destaque, mercê de infatigável operosidade e de imensa erudição, a personalidade marcante de José Xavier Carvalho de Mendonça, com o seu monumental Tratado de Direito Comercial Brasileiro. Em verdade, jamais seria demasiado lembrar que esse emérito comercialista exerceu entre nós influência idêntica à de Cesare VIvante, na Itália.

A quarta e última fase evolutiva do Direito Mercantil brasileiro, abrangendo os dois tumultuários decénios que conduzem aos nossos dias, vai gradativamente se avantajando em relação às anteriores.

$\mathrm{E}^{\prime}$ precisamente nesse periodo histórico que se destaca e toma vulto a obra do Professor Waldemar Martins FerREIRA. 
Constituindo-se ponto central de irradiação de ensinamentos doutrinários, visto que envolve os mais variados aspectos da moderna concepção do direito mercantil, impossível seria analisá-la particularizadamente, num trabalho de síntese desta espécie.

Tentaremos, por isso, em traços rápidos e perfunctórios, salientar apenas algumas de suas facetas de maior relevância, à guisa de justa homenagem ao Mestre insigne.

Ao legislador do Código de $\mathbf{1 8 5 0 ,}$, no que tange ao instituto das sociedades comerciais, não seria possível disciplinar a espécie hoje conhecida sob a denominação de sociedade por quotas de responsabilidade limitada.

E' que o princípio da limitação dos riscos, cujo processo evolutivo obedece a imperativos económicos inelutáveis, ainda se encontrava na fase ou estágio da sociedade anónima, então subordinada a normas bem rígidas e, pois, compratíveis com o espírito daqueles tempos.

Desse modo, não seria de esperar que nos antecipássemos a países de cultura jurídica multi-secular e de vida económica intensíssima, fazendo incluir, no sistema do Código, os lineamentos estruturais de um novo instituto que, aliás, só iriam aparecer doze anos depois, com o advento da lei inglesa de 7 de agosto de $\mathbf{1 8 6 2}$.

No entanto, três anos após o seu aparecimento na Inglaterra surgiu entre nós a primeira tentativa favorável à implantação das sociedades de responsabilidade limitada, por iniciativa do então Ministro da Justiça, NABuco DE Araujo.

Submetido o projeto de lei à consideração do Consetho de Estado, este o considerou prejudicial aos interesses nacionais e propôs a sua rejeição, com a qual se conformou - Imperador, pela resolução de 24 de abril de 1867.

"A admissão dessas sociedades - escreveu J. X. CARVALHo DE MENDONÇA - romperia a tradição, perturbaria 0 nosso sistema e não traria outras vantagens mais positivas 
além das que oferecem as sociedades anónimas e as comanditárias" (2).

Observe-se, de passagem, que o emérito comercialista, talvez por um apego exagerado à tradição, sempre se manifestou contrário ou reservado em relação à novidade legislativa, mesmo em época sobremodo propicia à sua inclusão no nosso direito positivo.

Mas, de qualquer forma, forçoso é reconhecer que a rigidez de certos princípios jamais terá força suficiente para tolher a marcha evolutiva dos institutos jurídicos reclamados pela ordem económica, os quais, uma vez vitoriosos, assemelham-se a actos de justificada rebeldia contra o tradicionalismo pré-existente.

Foi precisamente o que se verificou entre nós quanto ao instituto das sociedades por quotas de responsabilidade limitada.

Transformada a nossa fisionomia sócio-político-económica pela decorrência de mais de meio século em relação à data em que se dera aquela tentativa consubstanciada no projecto de Nabuco de Araujo, eís que se apresenta o momento psicológico favorável à adopção do novo tipo societário, já amplamente divulgado em outros países.

Em vista disso, quando o Deputado Joaquim Luís Osókio apresentou à Câmara Federal, em sessão de 20 de Agosto de 1918, projeto de lei instituindo as sociedades por quotas de responsabilidade limitada, passou o assunto a ser encarado sob um clima de indisfarçável simpatia e todas as possibilidades de rápida aprovação.

Submetido ao regime de urgência, de logo se transformou o projeto do parlamentar gaúcho no Decreto . $^{\circ}$ 3.708, de 10 de Janeiro de 1919.

f́ de salientar que ao próprio JoAQuim Luís Osório causou surpresa a circunstância de haver o seu trabalho

(2) Obr, cit., vol. III, pág. 58, in nota 1. 
transitado pelas duas Câmaras Federais sem maior exame e discussão, aliás indispensáveis a uma inovação legislativa de tal ordem, para que lhe fossem supridas as falhas e lacunas, que são muitas.

Por feliz coincidência, naquele mesmo ano de 1919 estreou, como publicista, o Doutor Waldemar Martins FerREIRA. E o fez já manifestando as duas qualidades que, mais tarde, iriam caracterizar-lhe a personalidade de jurista a extensão e a profundidade.

Manual do Comerciante - Os credores privilegiados e o direito de pedir a falência - A hipoteca naval no Brasil - O menor comerciante - Estudos de Direito Comercial - Sociedades por quotas - constituem o expressivo cartão de visita com que o novel comercialista ingressara na literatura jurídica do país, no decorrer de um ano apenas.

Desses seis trabalhos, em consonância com a ordem de jdéias que vimos desenvolvendo, merece especial destaque o último enumerado, por dois motivos prepionderantes.

Primeiramente, necessitava a nação conhecer as peculiaridades do novo instituto - sociedades por quotas - afim de que a lei, apesar das deficiências resultantes de sua apressada elaboração, pudesse realmente atingir a sua alta finalidade, quanto à sua aplicação imediata.

Depois, porque o Doutor Waldemar Ferreira imprimiu ao seu trabalho orientação segura, baseada no profundo conhecimento de leis idênticas vigorantes entre outros povos e na melhor doutrina sobre o assunto, de molde a torná-lo grandemente útil aos homens práticos do comércio, aos profissionais da advocacia e bem assim aos aplicadores. do Direito.

Defeituoso embora, o Decreto $n .^{\circ} 3.708$, de 10 de Novembro de 1919, vem ensejando maiores possibilidades à expansão do comércio honesto, sempre que os seus agentes procurem beneficiar-se com a limitação dos riscos inerentes à mercancia. 
Por outro lado, o advento do novo instituto é bem uma demonstração de que as realidiades da vida social jamais se: deixarão jugular pela couraça de certas teorias falsamente revestidas de uma suposta imutabilidade. Com efeito, os princípios não se podem superpor aos factos. Estes, pelo contrário, determinam o aparecimento das leis novas, cabendo aos doutrinadores interpretá-las cientificamente, para a sua perfeita aplicação.

A obra Sociedades por quotas, do Prof. Waldemar FerREIRA, teve o grande mérito de assegurar a eficácia do novo instituto, no âmbito do nosso direito positivo.

Constitui o seu maior elogio o facto, aliás raro entre nós, de haver circulado em quatro edições no ano de 1919 , em quinta e última, no de 1925, com os acréscimos e revisões considerados indispensáveis ou oportunos, pelo seu autor.

De como foram recebidos pela crítica especializada os trabalhos de estreia do Professor Waldemar Ferreira nos dá ciência o comercialista de maior relevo na época, J. X. CARvalHo DE Mendonç,A, quando, reportando-se aos Estudos de Direito Comercial, assim se manifesta:

"Não se trata de um livro escrito com outros livros, mas de uma obra original, recomendável pelo profundo conhecimento, revelado pelo autor, das nossas leis comerciais e dos princípios científicos que as informam, pelos conceitos assentados com segurança e simplicidade e ainda pela exposição amena, sempre em boa linguagem, das mais intrincadas e difíceis questões teóricas e práticas".

Essas judiciosas referências, firmadas por mestre de tão alto saber, explicam perfeitamente as razões por que alguns livros de estreia do incipiente publicista passaram a circular em sucessivas re-edições. 
Com efeito, além do êxito editorial de Sociedades por quotas, a que já fizemos menção, o Manual do Comerciante - colecção de pareceres originàriamente divulgados em revistas especializadas e, em 1919, enfeixados em volume - logrou tiragem duplicada em 1923 e mais uma outra, maior em quantidade de exemplares e acrescida em conteúdo, no ano de 1929.

Antes disso, porém, já se havia tornado acentuada e fecunda a actividade científica de Waldemar Ferreira, como estudioso dos problemas concernentes ao Direito Mercantil, no âmbito ilimitado de sua elaboração ou interpretação doutrinária.

Com a dissertação - O menor comerciante -- submeteu-se, em 1920, ao concurso para professor substituto da secção de Direito Comercial da renomada Faculdade de Direito de S. Paulo, assumindo, em 1925, a regencia interina da primeira cadeira dessa disciplina, de que, aliás, já possuia o título de livre docente.

De suas actividades iniciais no magistério, para o qual de logo manifestou irresistivel inclinaçâo, poderemos formular ideia bem nítida através da leitura de sua obra Curso de Direito Comercial.

Correção e simplicidade de linguagem, segura exposição metodológica, clareza de raciocínios e completo domínio da matéria - predicados essenciais ao mister de professor - são virtudes que ressaltam em toda a extensão desse compêndio, que abrange dois alentados volumes, ambos publicados em 1927.

Nesse mesmo ano, deu ainda à publicidade, duas obras de real merecimento - Da responsabilidade civil da massa falida por culpa dos seus representantes e Sociedades comerciais irregulares.

Nessa última monografia, hoje considerada obra rara, focaliza questões as mais importantes e debatidas, no terreno movediço das controvérsias doutrinárias. 
De inicio são levantadas as seguintes interrogações:

a) As sociedades irregulares são pessoas jurídicas̃ e os sócios de responsabilidade ilimitada são pessoas distintas da pessoa jurídica: sociedade?

b) Como se justifica que a falência da sociedade importe, ipso facto, a falência daqueles sócios?

c) Da responsabilidade dos sócios solidários pelas dívidas sociais: è uma responsabilidade solidária ou subsidiária?

As várias teses, consubstanciadas nesta sintese, são coordenadas em dez capítulos, todos expostos em linguagem clara, precisa e concisa, sob o influxo de processo metodológico admirável.

Importa salientar que o autor não se limita a sua exposição pura e simples, nem tão pouco se contenta com o reproduzir conceitos já expendidos, através de teorias uniformes ou divergentes.

Ao contrário disso - que lhe seria bem comodo - prefere o trabalho exaustivo de verdadeiro cientista, isto é, expõe, investiga, analisa, documenta e, por fim, chega a conclusões próprias e consentâneas com a lógica do direito.

Sociedades comerciais irregulares, portanto, é obra que merece ser lida e meditada por todos os estudiosos do Direito Mercantil, pois, além de versar problemas os mais completos e de esgotar a matéria, revela um excepcional equilíbrio dontrinário, qualidade que muito credencia ao seu ilustre autor.

Professor, advogado e jurisconsulto, com a vantagem de reunir os atributos de crescente notabilidade em qualquer desses sectores, Waldemar Ferreira teria inevitàvelmente 
de fazer realçar as suas qualidades personalíssimas, entre as quais o hábito do trabalho metódico, ininterrupto $\mathrm{e}$ construtivo, em constantes lucubrações a serviço do Direito Mercantil.

É hoje, em função disso, o mestre por excelência, a cujos ensinamentos todos recorrem, com o mesmo afã com que os sedentos se aproximam das aguas límpidas da fonte.

A simples enumeração de suas obras de doutrina, tanto mais numerosas quanto mais profundas, é bem uma demostração altiloquente e expressiva da mais fecunda operosidade.

Efectivado na cátedra de professor por Decreto de 24 de Outubro de 1927, dai por diante novos triunfos lhe estão reservados, em diferentes campos de actividade a que se devota.

Questões de Direito Comercial - 1. a série, 1929 - sôbre ser livro de clínica jurídica, em seu próprio dizer, é também apreciável condensação de ensinamentos os mais diversos aplicáveis à solução de casos concretos.

A nova lei de falência e a sua elaboração, S. Paulo 1930; O comércio marítimo e o navio, S. Paulo - 1931; $O$ conhecimento do transporte ferroviário, S. Paulo - 1932 -são outros valiosos títulos que se incorporam ao património bibliográfico do notável publicista.

Democrata por temperamento e conviccão, não se tem excusado ao dever cívico de exercer, em toda a sua ampli. tude, os inálienaveis e legítimos direitos de cidadão.

E sempre o fez com a valentia moral peculiar aos grandes espíritos, tornando nítidas e insofismáveis as suas atitudes e decisões.

De sua incisiva co-participação nos destinos da alta política nacional e da maneira desassombrada por que sempre se devotou à cultura cívica do Pais, dí-lo eloquentemente o já ter sido exilado no Exterior, em virtude de haver parti- 
cipado activamente do Governo Revolucionário de S. Paulo, no ano histórico de 1932.

Observe-se, no entanto, que o político jamais destruiu o jurista inato que nele reside.

Efetivamente, no seu repouso forçado em Portugal, alí realizou, no Salão dos Actos Grandes da Faculdade de Direito da Universidade de Lisboa, uma série de conferências para mestres e discípulos, as quais, em 1933, a Tip. da Empresa do Anuário Comercial da bela metrópole lusitana enfeixou em volume, sob a epigrafe de - As Diretrizes do Direito Mercantil Brasileiro.

"Foram, as cinco conferências, modelo de precisão" - declara o professor Dr. Abel de Andrade, insigne Diretor daquela tradicional Escola Jurídica.

"Waldemar Ferreira - acrescenta - disciplinou com largo e feliz espírito de generalização todos os problemas do direito mercantil.

"Inteligência clara, argumentação perspicaz, transparência de forma, exposição didática, modo de dizer atraente, técnica jurídica perfeita, discreta ilustração das leses, integração rigorosa dos institutos de direito mercantil nas respectivas e sucessivas condições económicas e políticas do Brasil, não sei, ao certo, o que mais elegantemente avulte nas conferências do Dr. Waldemar Ferreira.

“E a graça artística, as descrições sugestivas, o relêvo pictoral de tantas aquarelas dispersas gentilmente pela grave exposição doutrinária do professor de direito!"

Além da transcrição desses períodos lapidares, exarados à guisa de prólogo a uma bem articulada síntese do conteúdo das conferências de Waldemar Ferreira, não resistimos ao desejo de reproduzir palavras que, sobre As diretrizes do direito mercantil brasileiro, escreveu o Conselheiro Dr. Martins de Carvalho - Príncipe dos Advogados de Portugal: 
"Distingue-se o abalisado conferente pela magnifica disciplina a que, como professor, que é na massa do sangue, - consegue submeter os mais vastos assuntos, pela desenganada facilidade em arredar minudências parasitárias, fazer sobressair o substancial, e arraigá-lo duma vez na memória dos que o ouvimos.

E é para notar que este soberbo poder de sintese do professor eminente anda ao compasso de admiráveis dons de "eloquente, seguro e fecundo advogado", conforme as expressões dum dos mais famosos escritores de Quinhentos.

Se as conferências do professor Dr. Waldemar Ferreira foram monumentais lições de direito brasileiro, foram também admirável lição, a portugueses, de patriotismo português".

Esses consagradores julgamentos, proferidos por nomes de tão alta cultura e saber, já seriam o suficiente para amenizar os dissabores do exílio a que fora condenado o grande comercialista pátrio, mercê da prepotência de um Governo Ditatorial.

Quis, porém, o destino conceder-lhe mais ainda. E o fez de modo a enaltecer os seus méritos e a encher de justo orgulho a cultura jurídica do Brasil.

Efetivamente, houve por bem a douta Congregação da Faculdade de Direito da Universidade de Lisboa, ao concluir Waldemar Ferreira o curso de conferências alí realizado, conferir-lhe o grau de doutor honoris causa.

São do professor Dr. José Caeiro da Mata, Magnífico. Reitor da Universidade de Lisboa, as palavras que se seguem:

"Nos actos mais solenes das antigas Universidades os professores não se limitavam a aparecer com o traje comum académico. Desde muito cedo, a imposição das insignias correspondentes ao supremo grau universitário capelo, barrete com borla e anel - mais simples na Sor- 
bonne do século XIII, mais luxuoso nas Universidades da Península, sobretudo a partir do século XVII, constituia uma das mais festivas e mais solenes manifestações da vida académica.

Nesta festa de hoje, a Universidade de Lisboa confere a V. Exa.: o barrete, reminiscencia do antigo capelo de ramos e bácoro e de louro entrelaçados, à qual CAMões alude no Canto III dos Lusíadas, na estrofe 87, e que é o súmbolo da coroa triunfal dos notáveis trabalhos científicos de V. Exa.; o capelo representa bem o explendor da sua alta e notabilíssima cultura; o anel é o símbolo da nossa, dora-avante estreita confraternidade científica. Ao lado dos nomes dos eminentes Professores Dugurt, JosseraNd e LAMBert, o nome de V. Exa. fica indelèvelmente inscrito nos anais da velha Universidade de Lisboa."

Regressando do exílio, onde lhe fora tributada a mais expressiva homenagem a que um cientista pode aspirar o reconhecimento do mérito pelos homens de mérito Waldemar Ferreira de logo reatou o fio de suas múltíplas actividades interrompidas, na cátedra de professor universitário, na banca de advogado militante e nas competições político-partidárias.

Trouxe também, da Europa, a par de consoladoras recordações, o firme propósito de elaborar uma obra sistematizada e ampla, isto é, um grande tratado sobre a matéria jurídica de sua predilecção.

Essa nova preocupação deve ter sido directamente. influenciada pelo estimulo resultante das honrarias de que foi alvo e ainda, ou principalmente, pela advertência discretamente enxertada na parte final da bela página de crítica do eminente professor Dr. Barbosa Magalhães, que a seguir reproduzimos: 
"Waldemar Ferreira, quer como professor, quer como advogado, é um verdadeiro e autêntico comercialista que alia à cultura pròpriamente jurídica a cultura do economista, ao poder de síntese o espírito de observação e análise.

E este o depoimento dos seus numerosos livros, onde com igual competência e brilho são tratadas as questões puramente jurídicas e as questões de ordem técnico-comercial, e que vai ser confirmado pelas conferências, cujas súmulas revelam o espírito superior do jurisconsulto. Baseado no estudo da vida e através das instituições jurídicas, Waldemar Ferreira eleva-se aos momentosos problemas da política juridica e social.

Orientado por Vivante e Rocco, o Dr. Waldemar FerREIRA conhece a fundo os institutos económicos, que o direito comercial rege; e como comercialista erudito não ignora a vida comercial em todas as suas manifestações.

Waldemar Ferrreira, sem prejuízo da cultura jurídica geral, que possui em alto grau, conseguiu especializar-se como poucos; tem sido sempre professor de direito comercial, tem advogado sempre no foro comercial; tem escrito exclusivamente sobre direito comercial, sobre questôes jurídico-comerciais, que versa com profundeza de conhecimentos e com critério superior.

Em contacto permanente com a realidade da vida e com as obras dos mais notáveis comércialistas de todo o mundo, o seu espírito está admiràvelmente preparado para dar o maior rendimento.

Se ainda não produziu um grande tratado de direito comercial, nos seus numerosos e excelentes livros tem acumulado os materiais necessários para essa obra, que permita-se-nos dizê-lo - tem obrigação de fazer, para definitiva consagração do seu nome e para grande proveito de todos nós."

O desejo impreterível de corresponder a tão delicado apelo, a plenitude de energias criadoras aliada à posse de 
copioso e seleccionado cabedal bibliográfico indispensável à feitura de um trabalho daquele vulto, ensejaram, ao comercialista pátrio, a publicação do primeiro volume do Tratado de Direito Mercantil Brasileiro, em outubro de 1934.

Neste primeiro tomo, a que outros deveriam seguir-se, ainda conseguiu enfeixar as matérias concernentes ao conceito de comércio e suas divisões; definição e característicos do direito comercial e seu desenvolvimento histórico; fontes do direito comercial brasileiro e, por último, o conteúdo do direito comercial.

Mas, a título de justificativa à interrupção do esforço iniciado, relembra o autor, anos depois, que o homem põe e Deus dispõe.

Se isso é exato, certo é também que, mais uma vez, as actividades do político perturbaram as pesquisas do jurista, interceptando-lhe o trabalho tão auspiciosamente começado.

É que, em 1935, Waldemar Ferreira tomou assento na Câmara Federal, como representante do Estado de S. Paulo.

Na presidência da Comissão de Constituição e Justiça, para que fora escolhido, não se contentou apenas com o estabelecer e dirigir a ordem dos trabalhos a ela afectos. Deles participou assiduamente, a igual dos mais eficientes dos seus pares, até mesmo versando assuntos inteiramente estranhos à sua especialização.

O casamento religioso de efeitos civis, substancioso volume que publicou em 1935, é bem uma demonstração da proverbial operosidade e vasta erudição do mestre insigne.

Foi porém interrompida a sua carreira de político militante, com o advento do golpe ditatorial. de 10 de novembro de 1937, de que resultou o fechamento da Câmara Federal.

Não obstante, ainda em consequencia de sua actividade parlamentar, enriquecera-se a nossa bibliografia juridica 
com o aparecimento dos seguintes trabalhos, todos dignos de um grande mestre:

a) O loteamento e a venda de terrenos em prestaçōes, $1 .^{\circ}$ e 2. ${ }^{\circ}$ volumes - S. Paulo, 1938, nos quais é explanada e discutida a matéria consubstanciada em projecto de sua autoria, convertido no Decreto-lei $\mathrm{n}^{\circ}$ 58, de 15 de setembro de 1937 e regulamentado pelo Dec. $n .^{\circ} 3079$, de 15 de setembro de 1938;

b) Código das sociedades comerciais, S. Paulo 1938, de cujo projecto foi relator e ainda:

c) Princípios de legislação social e de direito judiciário do trabalho, constituídos de dois volumes, no primeiro dos quais (S. Paulo, 1938) defende ideias e princípios que, na qualidade de relator do projecto governamental, na Comissão de Constituição e Justiça da Câmara Federal, houve por bem adoptar, em vários pontos divergindo do autor do projeto e logrando vencê-lo, após acaloradas discussões de ordem doutrinária. No $20^{\circ}$ volume, já editado na vigência das leis que instituiram a Justiça do Trabalho e o Conselho Nacional do Trabalho (Liv. Editora Freitas, S. Paulo - 1939), procede o autor à exegese de cada um dos artigos do texto legal, à luz de concepções doutrinárias as mais autorizadas e acrescidas de conclusões próprias e originais, mercê de um processo de percuciente investigação cientifica.

Ainda naquele ano de 1939, quando, por mais um acto de força dos donatários momentâneos do Poder, foi afastado compulsòriamente do exercício de sua cátedra de professor, a que depois voltaria "também à sua revelia, como dela saíra e a despeito de suas inalteráveis convicções democráticas" - naquele mesmo ano, dizíamos, publicou Waldemar Ferreira o segundo tomo do Tratado de Direito Mercantil Brasileiro.

Já em vias de conclusão o terceiro, destinado ao estudo das sociedades comerciais, eis que surge o Decreto-Lei n. ${ }^{\circ}$ 
2.627, de 26 de Setembro de 1940, estabelecendo nova disciplina às sociedades por acções.

Em virtude disso, teve o mestre de refundir e actualizar o seu trabalho, dai advindo o Compêndio de Sociedades Mercantis.

A primeira edição, que circulou em 1940 e cułjos originais foram entregues ao editor apenas 22 dias decorridos da promulgação da lei, seguiu-se uma outra em três volumes, no ano de 1942 e, por último uma terceira, cuidadosamente revista e aumentada, em 1949.

A propósito deste compêndio assim se expressou o conceituado jurista cubano, professor ERnEsto DiHigo, da Universidade de Havana:

"No es un tratado de sociedades mercantiles, tal como estamos acostumbrados a concebir esa clase de obra, sino un libro que, en forma orgánica y metódica, estudia muchos de los problemas que puede ofrecer ese sector del derecho mercantil. Casi un centenar de cuestiones, muchas de ellas abarcando aspectos diversos, comprende el libro, cuestiones que, para mayor claridad, han sido agrupadas formando los diferentes capítulos que integrarían un tratado sobre sociedades. De especial interés son las páginas dedicadas a las compañias anónimas, no sólo por los temas en ellas tratado, sino también porque son un comentário al decreto-ley brasileño número 2.627 , de 26 de septiembre de 1940 , que regula esa clase de sociedades.

La obra está escrita en un estilo claro y atrativo. Tiene la doble ventaja de ser asequible, por la forma sencilla de su exposición, al mero comerciante que quiera ilustrarse sobre los problemas que le afecten, y de conservar, al propio tiempo, gran interés para el jurisconsulto, que acudirá siempre a sus páginas con fruto, pues en ellas encontrará las opiniones autorizadas del autor. Este revela, en todos los momentos, sólida preparación y un gran 
sentido jurídico, que o llevan a enfocar y resolver con justeza los problemas que se plantea" (3).

Acrescidas, assim, as letras juridicas nacionais, com trabalho de tamanha magnitude, contudo é de notar que, até ao aparecimento de sua segunda edição de 1942, ainda nos ressentíamos da ausência daquele grande tratado que Waldemar Ferreira estava na obrigação de elaborar, na oportuna e sutil advertência do jurista lusitano.

E' que o Tratado de Direito Mercantil Brasileiro, iniciado em 1934 e, pela segunda vez, interrompido em 1940, não ultrapassara ao segundo volume que, como o primeiro, ràpidamente se esgotara.

Actualizar e concluir essa obra seria tarefa dificílima, dada a pletora de novos decretos que então se promulgava. "Tudo aconselha que se deixe para outros dias trabalho de tanta responsabilidade e que reclama grande esforço e maior serenidade" - pondera judiciosamente o mestre. "A parada impõe-se. Não ha atenção capaz de resistir ao afã de por em dia o legislado. Nem os fichários bastam. As alterações se sucedem. Não era, em tais circunstâncias, propício prosseguir em obra, que pressupõe estabilidade jurídica, sistemática e duradoura, que deve ser" (4).

Premido por tais fatores, deu início à elaboração de suas Instituições de Direito Comercial que, a despeito do carácter de "curso sumário e sistemático, de cunho didático" que inicialmente pretendeu imprimir-lhes, é hoje o grande tratado que estava a dever a mestres e discípulos afeiçoados ao estudo da ciência do direito.

(3) Revista del Colegio de abogados de La Habana (Cuba), apud Waldemar Ferreira, Compêndio de Sociedade Mercantis, 3.a ed., vol. I, págs. 35 e 36 .

(4) Waldemar Ferreira - Instituições de Direito Comercial, Prefácio da $1^{\mathrm{a}}$. ed., pág. 14. 
Antes, porém, de apreciarmos alguns aspectos dessa obra impõe-se-nos o dever de mencionar um outro trabalho do ilustre mestre, em consonância com o critério crcnológico que vimos adotando.

Referimo-nos ao Tratado das Debênturas, cujo primeiro volume foi trazido à publicidade em 1944.

Constituem as debênturas - ou obrigações ao portador - uma classe específica de títulos de crédito expedidos ern série, por sociedades anónimas, comanditárias por acções e bem assim pelas que lhes são equiparadias — mediante uma garantia comum.

Utilizando-se desse engenhoso sistema creditório, ditas empresas poderão adquirir os recursos pecuniários de que necessitam, já para possibilitar maior amplitude ao âmbito de seus negócios, já para resolver dificuldades financeiras que possam advir, já para conseguir o encampamento de empresas congéneres e, assim, evitar-lhes a concurrência.

Em casos tais, o aumento de capital por meio de nova emissão de ações tornar-se-ia desvantajoso, pela consequente diminuição de dividendos aos respectivos acionistas.

Por outro lado, a aquisição de numerário por meio de empréstimos bancários - via de regra concedidos a curto prazo - ainda não resolveria satisfatòriamente o problema, eis que reformas sucessivas teriam de ser processadas, até que a empresa reajustasse a sua situação económico-financeira e prescindisse do auxílio de capitais estranhos.

Daí as vantagens decorrentes do empréstimo por meio de emissão de títulos ao portador ou debênturas — verd'adeiro contrato especial de mútuo, pois que o montante da importância mutuada, acrescida de juros correspondentes, é fragmentado em pequenas parcelas, representadas por titulos negociáveis, cujo resgate se irá operando paulatinamente, mediante um processo gradual de amortização, na forma previamente estabelecida. 
Assunto pouco versado e de escassa bibliografia, se bem que de enorme relevância para o mundo capitalista, é bem de ver a grande utilidade do Tratado das Debênturas, do professor Waldemar Ferreira, que, apesar de ainda não concluído, já preenche sensível lacuna em nossa literatura jurídico-comercial.

Anunciando o aparecimento de quatro volumes das Instituições de Direito Comercial, o eminente jurista Dr. Eduardo J. Couture, Professor da Universidade de Montevideo, inseriu em sua crítica os períodos que se seguem:

“A un libro de Instituiciones no se llega sino después de un largo processo de preparación. Aunque parezca mentira, es más fácil escribir un tratado que unas instituiciones. Én el primero están todos los materiales; en el segundo deben estar los mejores materiales. La selección, la condensación y la limitación son los grandes méritos de una obra de esta índole a la que no puede llegar un profesor sino después de árduas instancias de preparación y de estudios" (5).

Essas interessantes observações ajustam-se perfeitamente à obra do comercialista patrício.

Em verdade, não se trata de mera reprodução de trabalhos anteriormente publicados, dos quais as Instituições muito diferem, tanto na forma quanto na substância.

Planificadas inicialmente em três volumes, correspondentes às três séries em que a disciplina jurídica do comércio é ministrada na Faculdade de Direito de S. Paulo - abrangem hoje cinco tomos refertos de material seleccio-

(5) Apud Waldemar Ferreira - Instituições de Direito Comercial, 2a ${ }^{a}$ ed., vol. 4\%., pág. 7. 
nado, lògicamente urdido e cuídadosamente analisado, à luz de um método expositivo racional e seguro.

Linguagem amena de frases curtas e incisivas; completo expurgo do supérfluo para que realce o essencial são outras tantas peculiaridades que avultam nas Instituições de Direito Comercial, imprimindo-lhes um cunho de específica originalidade.

Em vista disso, não lhes tem regateado encomios a crítica especializada, notadamente a estrangeira.

São de autoria do comercialista francês JEAn Escarra, Professor da Faculdade de Direito da Universidade de Paris, essas judiciosas considerações:

"L'ouvrage de M. W. Martivs Ferreira contient un tableau complet et à jour du droit brésilien. L'auteur est très averti des travaux de la doctrine étrangère et ses commentaires font également honneur à sa science juridique tt à ses connaissances pratiques. On notera dans ces volumes d'interessants indications sur l'évolution du droit commercial brésilien, une présentation vivante de la figure juridique du commerçant, le commentaire détaillé du decret-loi n. 2.627, du 26 septembre 1940, sur les sociétés anonymes, enfin une étude particulièrement bien venue de la garantie des droits de propriété industrielle". (6)

Nesse mesmo diapasão se faz ouvir a voz autorizada do Dr. Sagunto F. Perez Fontana, Professor de Direito Comercial da Faculdade de Direito da Universidade de Montevideo:

"El autor expone los caracteres principales de los diversos institutos que estudia, y a pesar del carácter de la obra, lo hace con amplia exposición de las doctrinas más modernas y la legislación más reciente.

Con su estilo característico, compuesto de frases breves $\mathrm{y}$ cortantes $\mathrm{y}$ afirmaciones categóricas que revelan el

(6) Revue Trimestrielle de Droit Commercial, Paris - 1948, vol. 1, pág. 206. 
caráter combativo del autor y la firmeza de sus convicciones, tanto en el campo científico como en la lucha por la afirmación de los principios democráticos de los que el Profesor Waldemar Ferreira es un ardiente defensor, realiza una obra de gran interés para los estudiosos del Derecho Comercial.

Las Instituições de Direito Comercial llenan perfectamente la finalidad que se propuso el autor al escribirlas, expresadas en el prefación de la primera edición. Los estudiantes encontrarán en esa obra los principios fundamentales de los diversos institutos que comprende el Derecho Comercial, expuestos con claridad y con amplia información legislativa, no sólo brasileña sino extranjera.

Sin recargar las citas, la obra contiene una rica información bibliográfica referida principalmente a los autores más modernos sin descuidar las obras clássicas de Derecho Comercial" (7).

Se nomes tão ilustres e de alta projecção internacional assim se manifestam, razões assistem aos juristas nacionais em reconhecer, na obra excepcional do comercialista brasileiro, as virtudes do autêntico cientista e as qualidades personalíssimas do Mestre.

E' que as Instituições de Direito Comercial, sôbre constituirem precioso repositório de ensinamentos utilíssimos, excedem de muito aos fins didáticos a que se destinam e passam a reflectir, de maneira inconcussa, a inestimável contribuição pessoal do Professor Waldemar Martins FerREIRA à evolução doutrinal do nosso Direito Mercantil.

(7) Apud Waldemar Ferretra - Instituições de Direito Comercial, $2^{\text {a }}$. ed., $3^{\circ}$ vol., págs. 7 e 8. 